\title{
Adaptive support ventilation
}

\author{
Ugur Koca $^{1 *}$ and Burcu T Demirdoven ${ }^{2}$ \\ ${ }^{1}$ Dokuz Eylül Univercity School of Medicine, Turkey \\ ${ }^{2}$ Buca Seyfi Demirsoy Hospital Emergency Service, Turkey
}

\begin{abstract}
Adaptive support ventilation (ASV) is a closed-loop ventilation mode. Breath-to-breath dual control is applied. The factors that determine the amount of ventilatory support provided by the ventilator, the patient's measured pulmonary mechanical properties and the patient's pale effort stop. Forced breaths are machine-triggered, pressure-targeted, and time-cycled. As the target frequency is approached with spontaneous breaths, mandatory breaths decrease. Tidal volume, which is adapted to breath-to-breath lung mechanics, automatically removes the patient from the pressure support (weaning) as the patient's lung mechanics and breathing efforts improve. The ASV algorithm determines the optimal respiratory pattern (VT and frequency) optimal for the patient by applying the concept of minimal respiratory work defined by Otis in 1950. This concept predicts breathing with VT and frequency, which minimalizes the cumulative effects of elastic and resistive loads created by the respiratory system and added to the system. Proper alveolar ventilation is provided while reducing the respiratory work of the patient and the ventilator. Since ASV can provide full or partial respiratory support, it can be used from the beginning of mechanical ventilation to weaning. ASV is a rule-based mode that guides the patient using the optimal breathing pattern to achieve minimum minute ventilation.
\end{abstract}

\section{Introduction}

ASV is a closed-loop ventilation mode. Dual control is applied from breath to breath. The factors that determine the amount of ventilatory support provided by the ventilator are the patient's measured pulmonary mechanical properties and the patient's pale effort. ASV is a pressure-controlled intermittent-mandatory form of ventilation, has the control software for tidal volume, breath frequency and minute volume. ASV switches from pressure control to SIMV or PSV, depending on the patient's condition. Unlike PCV, SIMV and PSV, ventilation volume is kept under control and the following is guaranteed [1]:

1. Minimum minute ventilation set by the user

2. Effective tidal volume on the calculated theoretical dead space of the patient

3. Minimum breath frequency

Mandatory machine breaths are triggered when spontaneous breath effort falls below its optimum breath rate:

1. Mandatory breaths are machine-triggered, pressure-targeted and time-cycled.

2. The optimal breath rate is calculated according to the dead space I tidal volume ratio and expiratory time constant to produce a minimum breath job.

3. The pressure target of the mandatory breaths is calculated as the pressure required to reach the target tidal volume obtained by dividing the target minute ventilation volume by the optimum breath.

4. As the expiratory time constant is obtained by multiplying compliance and resistance, ASV determines the optimum respiratory rate and tidal volume based on the patient's obstructive and restrictive features. [1,2]
The optimal tidal volume and frequency are determined based on the ideal weight and\% min volume information entered.

The following is used to determine this target ventilatory pattern:

1. Set $\%$ min volume setting

2. Theoretical dead space

3. Expiratory time constant of the respiratory system

4. If the expiratory time constant is short (restrictive), low tidal volume and high frequency are selected.

5. If the expiratory time constant is long (obstructive), high tidal volume low frequency is selected.

6. The expiratory time constant is also used to determine the inspiratory Time.

In obstructive cases with low expiratory rate with a high risk of autoPEEP development, the inspiratory time is kept short and expirium is extended. Theoretical dead space is used to calculate the minimum tidal volume to avoid ineffective alveolar ventilation. The targets for tidal volume and frequency are compared with the actual values reached in each breath and automatically decided for [1-3]:

\section{Start time of the next mandatory breath}

2. The amount of inspiratory pressure to be applied on PEEP in the next breath Mandatory breaths decrease as spontaneous breaths

${ }^{\star}$ Correspondence to: Ugur Koca, Dokuz Eylül Univercity School of Medicine, Department of Anesthesiology and Reanimation, İntensive Care, Turkey, Tel: + 90 (505) 83123 83, Email: ugur.koca@deu.edu.tr

Key words: adaptive, ventilation

Received: April 20, 2020; Accepted: May 04, 2020; Published: May 12, 2020 
approach the target frequency. Thanks to the tidal volume adapted to the respiratory lung mechanics, the patient's lung mechanics and pale efforts are automatically removed from the pressure support (weaning). Conversely, as the patient's lung mechanics worsen and his breath effort decreases, the ventilator automatically increases the mandatory breath support. In ASV, the patient has a high breath freedom with each breath, because the control unit acts as a controller of inspiratory pressure and never forces to give a certain current. Minimum minute ventilation is guaranteed in ASV. The patient is free to raise the minute ventilation above the user-set goals.

\section{Purpose of ASV [1,4]:}

1. Reducing the breathing work of the patient and the ventilator while ensuring proper alveolar ventilation.

2. ASV can be used from the beginning of mechanical ventilation to weaning since it can provide full or partial respiratory support [5].

3. ASV is a rule-based mode that guides the patient using the optimum breathing pattern to achieve minimum minute ventilation [6].

\section{Rules can be hard and soft:}

1. Hard rules are not affected by the user's inputs and the characteristics of the patient, pre-setting limits on respiration

2. Soft rules are affected by the inputs of the user and the measured characteristics of the patient, and they differ with the change of inputs and patient characteristics over time.

3. Clinician determines the minimum minute target ventilation by entering the patient's ideal weight (IBW) and\% minute volume (\% min vol) control

4. ASV determines the tidal volume and frequency that will provide the minimum breath work according to the Otis equation.

5. While the patient is breathing spontaneously (pressure support breaths), only determines the inspiratory pressure level that will provide the target tidal volume.

6. Determines the tidal volume and breath frequency that will reach the target minute ventilation while the patient has no spontaneous breath (mandatory breath).

7. Since the tidal volume and respiratory frequency are inversely related $(\mathrm{Ve}=\mathrm{Vt} \mathrm{X}$ fr) for a fixed minute volume, the breathing work associated with resistance increases while the breathing work associated with resistance increases while the breathing frequency increases (inspiratory time decreases).

8. Total breathing work, which is the sum of resistive and elastic breathing jobs, is normally at a minimum value of $12-15$ breaths per minute for adults.

9. As the breathing rate decreases, elastic work increases due to the high tidal volume formed.

10. As the breathing rat increases, resistive work increases due to high flow rates and trubence.

(Ideal body weight) IBW can be entered between 10-200 kg and calculated as (1.6):

IBW $=50+2.3$ (height- 60 in inches) in men

$\mathrm{IBW}=45.5+2.3$ (height -60 in inches) in women
- IBW is used theoretically to calculate the amount of dead space of the patient; $2.2 \mathrm{ml} / \mathrm{kg}$

- IBW also enables high (15.4xIBW) and low (4.4xIBW) tidal volume limits.

The low tidal volume limit is taken twice as dead space ventilation (2.2xIBW). The\% minute volume setting allows to set the target minute ventilation. Target minute ventilation (target $\mathrm{Ve})(\mathrm{l} / \mathrm{min})$ is determined by the $\%$ minute volume control using the normal Ve (100 $\mathrm{ml} / \mathrm{kg} / \mathrm{min}$; for IBW $>15 \mathrm{~kg}$ and $200 \mathrm{ml} / \mathrm{kg} / \mathrm{min}$; for IBW $<15 \mathrm{~kg}$ ) definitions:

target $\mathrm{Ve}(\mathrm{l} / \mathrm{min})=\mathrm{IBW} \mathrm{x} \% \mathrm{~min} \mathrm{vol} / 1000 \mathrm{IBW}>$ for $15 \mathrm{~kg}$

target $\mathrm{Ve}(\mathrm{l} / \mathrm{min})=\mathrm{IBW} \mathrm{x} \% \mathrm{~min}$ vol $/ 500 \mathrm{IBW}<15 \mathrm{~kg} \mathrm{100 \%} \min$ vol fits normal Ve.

The $\%$ min vol can be adjusted between $25-350 \%$ to accommodate increased dead space increases and VCO2 caused by V / Q disturbance. Setting the\% min vol also determines the high mandatory breathing frequency with soft rules:

Max mandatory frequency $=22$ breaths $/ \mathrm{min} x \% \min v o l / 100$ IBW $>$ for $15 \mathrm{~kg}$

Max mandatory frequency $=45$ breaths $/ \min \mathrm{x} \% \min$ vol $/ 100$ IBW for $<15 \mathrm{~kg}$

Hard limits for mandatory breaths are 5-60 (mim-max). Since the minimum mandatory breath number is 5 , the maximum mandatory tidal volume depends on the target Ve.

$\max \mathrm{Vt}=$ target $\mathrm{Ve} / 5$

The ASV algorithm determines the optimal respiratory pattern (Vt and frequency) for the patient by applying the minimum respiratory job concept defined by Otis in 1950. This concept predicts inhalation with $\mathrm{Vt}$ and

frequency, which minimizes the cumulative effects of elastic and resistive loads created by the respiratory system and added to the system. The following formula (Otis minimal work concept) determines the optimal frequency (1.6):

$$
\mathrm{f}=[1+2 \times \mathrm{a} \times \mathrm{RCe} \times(\mathrm{Ve}-\mathrm{f} \times \mathrm{Vd}) / \mathrm{Vd}-1] / \mathrm{a} \times \mathrm{RCe}
$$

F: breathing frequency

RCe: expiratory time constant (airway resistance X Crs); Ve: minimum minute ventilation

Vd: dead space ventilation; a: factor based on flow pattern, 0.329 for sinusoidal currents

$\mathrm{Vt}$ matching the result of the equation is calculated as follows:

\section{$\mathrm{Vt}=$ Min vol / $\mathrm{f}$}

According to this equation, the ASV algorithm selects the highest frequency and lowest Vt for restrictive patients, while it selects the lowest frequency and highest $\mathrm{Vt}$ for obstructive patients. If the patient's inspiratuar effort is not detected, the system will operate with pressure limit, volume target and time cycle (dual pressure-controlled breaths). The inspiratuar pressure of each mandatory breath is determined by the pressure / volume relationship measured in the previous breath. Insp pressure is adjusted with $2 \mathrm{cmH} 2 \mathrm{O}$ steps in each breath to give target tidal volumes. The minimum inspiratuar pressure is $5 \mathrm{~cm} \mathrm{H} 2 \mathrm{O}$ above the baseline pressure. The high-pressure limit (Pmax) set by the 
user is perceived as max insp pressure. The ASV controller detects max insp pressure at a maximum of $10 \mathrm{cmH} 2 \mathrm{O}$ below the set high pressure limit $[1,2]$.

For example: If Pmax is set to 45, ASV detects the pressure target as 35. If the target $\mathrm{Vt}$ cannot be given with the insp pressure limitation set by the clinician, an alarm sounds, and a message is given; Check P-high limit.

1. The high-pressure limit $(\mathrm{P} \max )$ set by the user is perceived as max insp pressure.

2. The ASV controller detects max insp pressure at most, $10 \mathrm{cmH} 2 \mathrm{O}$ below the set high pressure limit.

According to ASV's hard rules, min and max inspr times are 0.5 and 2 seconds. In practice, the ASV algorithm approximates the I / E ratio to $1 / 1$ for restrictive patients and to için for obstructive patients. RCe based expr time selection protects from autoPEEP by providing almost all of the exhalation up to the pulmonary equilibrium point. When the patient's effort is detected, it works with ASV pressure limit volume target and flow cycle (dual controlled PS breath). ASV automatically decreases mandatory breaths as patient involvement increases towards target Ve. ASV continues to target the optimal breathing pattern also in spontaneous breathing, and the only parameter controlled by ASV is Vt. Application $[1,2,6]$ :

1. When starting ASV, IBW and\% min vol are entered to calculate target Ve. In addition, appropriate PEEP-CPAP, FiO2 and timing sensitivity are entered.

2. Alarms are adjusted according to the patient and particular importance is given to Pmax. Pmax determines the upper limit of $\mathrm{Vt}$ to be given during ASV. It is recommended to start ASV with 45 $\mathrm{cmH} 2 \mathrm{O}$. This setting limits the highest target insp pressure to 35 .

3. ASV gives 5 pressure limit test breaths at baseline with 10-15 frequencies (according to set IBW) and baseline pressure (PEEP) with $15 \mathrm{cmH} 2 \mathrm{O}$ :

During this period, dynamic compliance measures RCe, Vt and breathing frequency and uses these measurements to determine the initial breathing frequency and Vt. After determining the breathing frequency and $\mathrm{Vt}$, a safety box; is created according to ASV rules.

- A: high tidal volume limit: Vt applied by ASV is determined by two settings: high pressure alarm limit and IBW and the highest recommended plateau pressure is $35 \mathrm{cmH} 2 \mathrm{O}$. To achieve this goal in ASV, the pressure limit must be set to 45 . For example: $70 \mathrm{~kg}$ postop patients, compliance $50 \mathrm{ml} / \mathrm{cmH} 2 \mathrm{O}$, PEEP 5 , high pressure limit 45; Pressure to be applied by ASV is $30 \mathrm{cmH} 2 \mathrm{O}$ and max Vt $=30 \times 50=1500 \mathrm{ml}$. If its compliance is $30 \mathrm{ml} / \mathrm{cmH} 2 \mathrm{O}$, it will be formed $\max \mathrm{Vt}=30 \times 30=900 \mathrm{ml}$. If the high-pressure limit is set to a value such as 60 , a secondary restrictive criterion takes over and protects it from excess Vt: $22 \times 1 b$

For this patient, the $\max \mathrm{Vt}=22 \times 70=1540 \mathrm{ml}$

B: low Vt limit: The minimum target Vt in ASV is determined by the formula $4.4 \times \mathrm{IBW}$ according to the set IBW. It is $308 \mathrm{ml}$ for $70 \mathrm{~kg}$ of patients. The danger at low Vt is inadequate alveolar ventilation. determining the parameters of alveolar ventilation is the volume of dead space. Vt must be greater than dead space volume.

Dead space ventilation is calculated as follows: $2.2 \mathrm{Xibw}$. The lowest $\mathrm{Vt}$ is taken at least 2 times this value: $4.4 \mathrm{xibw}$

\section{C: high frequency limit:}

Determining parameters:\% min vol and IBW

$\mathrm{fmax}=$ target $\mathrm{Ve} / \min \mathrm{Vt}$

For $70 \mathrm{~kg}$ of patients fmax $=7000 / 308=22$ (when $\min \% 100$ is vol). If $\% \min$ vol is set to $350 \%, f \max =24500 / 308=77$.

ASV operates the safety mechanism that considers the patient's exhalation ability to protect the patient from these high frequencies. The measure of exhalation ability is expiratory time constant (RCe). At least $2 \mathrm{RCs}$ are required to ensure exhalation up to the elastic balance point of the respiratory system ( $90 \%$ of maximum potential volume change). For this purpose, ASV calculates the maximum respiratory rate by accepting the minimum insp time $1 \mathrm{RCe}$ and the min exp time 2 RCe with the formula:

$\mathrm{fmax}=60 /(3 \mathrm{xRCe})=20 / \mathrm{RCe}$

fmax \&\#8804; 60

For example: $70 \mathrm{~kg}$ patient, $\mathrm{Crs}=50 \mathrm{ml} / \mathrm{cmH} 2 \mathrm{O}(=0.05 \mathrm{~L} /$ $\mathrm{cmH} 2 \mathrm{O}$ ), Raw $=5 \mathrm{cmH} 2 \mathrm{O} / \mathrm{L} / \mathrm{sn}$, Rdevre-valv $=5 \mathrm{cmH} 2 \mathrm{O} / \mathrm{L} / \mathrm{sn}$

$\mathrm{RCe}=0.05 \times(5+5)=0.5 \mathrm{~s}$

$\mathrm{Fmax}=20 / 0.5=40$

D: low frequency: The lowest frequency is fixed and 5.

At $100 \%$ min vol setting, the lowest frequency (5) limits the max Vt to 1400 for $70 \mathrm{~kg}$ of patients $(7000 \mathrm{ml} / 5=1400)$.

Optimal breathing pattern: it fits completely unsupported breathing that the patient naturally chooses and gives the breathing pattern that the patient can maintain.

\section{Calculates the frequency from the ASV Otis equation:}

For example: $70 \mathrm{~kg}$ of patients, $100 \% \mathrm{~min}$ vol, $\mathrm{RCe}=0.5 \mathrm{sec}$, optimal $\mathrm{f}=15$.

Target $\mathrm{Vt}=$ target $\mathrm{min}$ vol $/$ optimal $\mathrm{f}=7000 / 15=467 \mathrm{ml}$

When the ventilator detects spontaneous breathing effort, the ASV algorithm responds by reducing the mandatory breathing rate. ASV guides the patient to the target breathing pattern by manipulating the insp pressure during spontaneous breathing. In this case, each breath pressure limit, flow cycle (as in PSV) and volume is targeted. The patient breathing above target $\mathrm{Ve}$ occurs when the patient frequency is above the target frequency, because ASV maintained the target Vt and the pressure limit for this target. The specified target point may be outside the security box. In this case, ASV selects the closest point in the safety box and alerts the clinician with an alarm: check\% min vol, unable to reach target, ASV: check P-high limit. When ASV reaches steady state, blood gas control should be performed. Follow-up (ss> 35), clinically respiratory distress findings (accessory muscle use, abdominal-thoracic paradox movement, intercostal pull) are considered as inappropriate breathing patterns. As patient effort occurs and lung mechanics improve, automatic and continuous weaning occurs with ASV. When minimal ASV settings are determined, the patient's separation from the ventilator is evaluated. Minimal settings for the ASV algorithm; there is no mandatory breath and the insp pressure baseline is

above $8 \mathrm{cmH} 2 \mathrm{O}$. How ASV starts, starting breaths:

Question: How to achieve target values for a patient without knowing whether the patient is breathing spontaneously? 
For this purpose, ASV implements SIMPV (forced pressure ventilation from synchronized intermittent). Every breath triggered by the patient is supported with a flow cycle and the transition to exhalation is adjusted according to the flow. If the patient does not trigger breathing, the given breath pressure is adjusted, and time cycled.

The following must be set by the user:

\section{PEEP Oxygen}

Pramp

Expiratory timing sensitivity

Trigger type and sensitivity

The following is set automatically by ASV and the user cannot be confused:

SIMV frequency: to change the total breathing frequency

Inspiratory pressure level: To change the inspiratory volume

Inspiratory time: to supply gas to the lungs

\section{Initial breathing pattern}

\section{References}

1. Brunner JX, Iotti GA (2002) Adaptive Support Ventilation (ASV). Minerva Anestesiol 68: 365-368. [Crossref]

2. Campbell RS, Branson RD, Johannigman JA (2001) Adaptive support ventilation Respir Care Clin N Am 7: 425-440. [Crossref]

3. Wong WT, Gomersall CD (2017) Adaptive support ventilation of cardiac surgical patients: A component of a complex intervention. J Crit Care 37: 251. [Crossref]

4. Jaber S, Sebbane M, Verzilli D, Matecki S, Wysocki M, et al. (2009) Adaptive support and pressure support ventilation behavior in response to increased ventilatory demand. Anesthesiology 110: 620-627. [Crossref]

5. Cassina T, Chiolo R, Mauri R, Revelly JP (2003) Clinical experience with adaptive support ventilation for fast-track cardiac surgery. J Cardiothorac Vasc Anesth 17: 571575. [Crossref]

6. Kirakli C, Naz I, Ediboglu O, Tatar D, Budak A, et al. (2015) A randomized controlled trial comparing the ventilation duration between adaptive support ventilation and pressure assist/control ventilation in medical patients in the ICU. Chest 147: 15031509. [Crossref]

Copyright: (C2020 Koca U. This is an open-access article distributed under the terms of the Creative Commons Attribution License, which permits unrestricted use, distribution, and reproduction in any medium, provided the original author and source are credited. 